no significant difference has been found between survival in the two groups in clinical stage I cases, those with stage II tumours showed a statistically better survival in the radical mastectomy group at 10 years, though this was not seen after 5 years. A significantly greater rate of local recurrence was observed in the tylectomy group than in those undergoing radical mastectomy, but there was a higher incidence of lymphoedema of the arm in the radical mastectomy group.

Only when all the permutations and combinations of treatments carried out in various centres on patients with breast cancer have been submitted to such thoroughly controlled investigation will surgeons be in a position to judge the best possible treatment for an individual patient with this disease.

\footnotetext{
1 Halsted, W. S., Annals of Surgery, 1894, 20, 497.

2 Forrest, A. P. M., British fournal of Surgery, 1969, 56, 782

3 Johnstone, F. R C., Surgery, Gynecology and Obstetrics, 1972, 134, 211

4 Galasko, C. S. B., Annals of the Royal College of Surgeons of England, $1972,50,3$.

Bloom, H. J. G., in Prognostic Factors in Breast Cancer, ed. A. P. M. Forrest and P. B. Kunkler, p. 3. London, Livingstone, 1968.

Kaae, S., and Johansen, H., in Prognostic Factors in Breast Cancer, ed. A. P. M. Forrest and P. B. Kunkler, p. 93. London, Livingstone, 1968. Fisher, B., in Surgery Annual, 1971, 3, p. 227, ed. P. Cooper and L. M. Nyhus. New York, Appleton, 1971 .
}

\section{Nutrition and Sleep}

"Very extraordinary boy. . . . Goes on errands fast asleep, and snores as he waits at table . . . a wonderfully fat boy." Charles Dickens penned the first description of the Pickwickian syndrome, a syndrome that provides one of many intriguing links between nutrition and sleep. Though patients suffering from it may be improved by dieting their basic disorder is a neurophysiological one that gives rise to overeating, to daytime sleepiness, and to characteristic nocturnal sleep made up of an endless sequence of apnoea, abortive grunts, and explosive snorts. ${ }^{1-3}$

Overpowering sleepiness is also a feature of the more common narcoleptic syndrome. In some patients the onset of this disorder is abrupt and is then often associated with a rapid gain in weight. ${ }^{4}$ The obesity is secondary, and slimming improves neither the attacks of sleepiness nor the cataplectic episodes characterized by loss of muscle tone. Yet another association between sleepiness and nutrition is found in examples of the Kleine-Levin syndrome, in which periods of days or weeks of inertia are associated with voracious eating. ${ }^{56}$ In contrast are the effects of the amphetamine derivatives used for appetite and weight reduction, all of which, even diethvlprovion ${ }^{7}$ and fenfluramine, ${ }^{8}$ may cause reduced or restless sleep. Severe weight loss and restlessness are also features of anorexia nervosa, and A. H. Crisp ${ }^{9}$ drew attention to the poor sleep of these patients and proposed that insomnia in this and other psychiatric disorders might have a nutritional origin and not just an anxiety basis. It may be noted that rats kept without food sleep less and less and become totally insomniac after six to eleven days. ${ }^{10}$

Recently Crisp and his colleagues ${ }^{11}$ studied the sleep of patients with anorexia nervosa before and after treatment. After refeeding for six to twelve weeks the patient spent significantly less time awake or drowsy in the night, and the E.E.G. stage of sleep, characterized by the largest electrical slow waves and usually called stage 4 sleep, greatly increased. This stage of sleep has a number of known metabolic associations: it is enhanced by thyroid hormone, 12 has been found to be increased after exercise in trained athletes, ${ }^{13}$ and seems to govern nocturnal growth hormone secretion $^{14}{ }^{15}$-all of which suggest an anabolic and restorative role for this stage of sleep.

A glass of hot milk is a traditional remedy for sleeplessness. Relaxation arising from warmth, a childlike feeling of being pampered, or alternatively a response to the consummation of a basic drive may explain this. It is commonly believed that a good meal or coitus lead to sleepiness, and certainly male rats sleep much more after sexual activity. ${ }^{16}$ But a more specific response is suggested by the work of J. W. Fara and colleagues. ${ }^{17}$ They found that the introduction into the duodenum of fat in the form of milk or corn oil enhanced sleep in cats, and from this they suggested that a gastrointestinal hormone could be responsible for promoting sleep. The authors of the papers printed at pages 429 and 431 of this journal report that their investigations, though they used different methods, show that sleep is less restless or less broken after a bedtime hot milk-cereal beverage that for many years has been claimed to improve sleep. The apparent effect of the drug was greatest in the latter part of the night. In an era of heavy prescribing of hypnotic drugs this is a welcome finding.

The dearth of knowledge about digestive and metabolic processes during the large part of our lives we spend asleep emphasizes the need for further research.

\footnotetext{
Schwartz, B. A., Seguy, M., and Escande, J.-P., Revue Neurologique, $1967,117,145$

Kuhlo, W., Archiv für Psychiatrie und Zeitschrift f. d. ges. Neurologie, 1968, 211, 170

Hishikawa, Y., Furuya, E., and Wakamatsu, H., Folia Psychiatrica et Neurologica f̆anonica, $1970,24,164$.

Daniels, L. E., Medicine (Baltimore), 1934, 13, 1.

Critchley, M., Brain, 1962, 85, 627.

- Garland, H., Sumner, D., and Fourman, P., Neurolog v, 1965, 15, 1161

Oswald, I., Jones, H. S., and Mannerheim, J. E., British Medical Journal, $1968,1,796$.

Lewis, S. A., Oswald, I., and Dunleavy, D. L. F., British Medical Fournal, $1971,3,67$.

- Crisv, A. H., Fournal of Psychosomatic Research, 1967, 11, 117.

10 Jacobs, B. L., and McGinty, D. J., Experimental Neurology, 1971, 30, 212. Crisp, A. H., Stonehill, E., and Fenton, G. W., Postgraduate Medical Fournal, 1971, 47, 207.

2 Kales, A., et al., fournal of Clinical Endocrinology and Metabolism, 1967, 27,1593

${ }^{13}$ Baekeland, F., and Lasky, R., Perceptual and Motor Skills, 1966, 23, 1203.

14 Sassin, I. F., et al., Science, 1969, 165, 513.

15 Sassin, J. F., et al. Life Sciences, 1969, 8, Part 1, No. 23, p. 1299.

16 Boland, B. D., and Dewsbury, D. A., Physiology and Behaviour, 1971, 6, 145.

${ }^{17}$ Fara, J. W., Rubinstein, E. H., and Sonnenschein, R. R., Science, 1969, $166,110$.
}

\section{Analgesia for Burnt Patients: A Symposium}

Ever since man discovered fire he has been liable to injury by burning. The advance of civilization, particularly since the Industrial Revolution, has increased this liability owing to the growing use of electricity, gas, and chemicals as well as fire. Innumerable attempts have been made to control the pain associated with it, but until recent years they have been largely unsuccessful owing to the difficulty of applying effective analgesia without disturbing the feeding pattern of the patient.

The establishment and increasing technical refinement 